\title{
Improved strength and reduced permeability of stabilized peat: Focus on application of kaolin as a pozzolanic additive
}

\author{
Leong Sing Wong, Roslan Hashim, Faisal Ali
}

Introduction

Kaolin is a subgroup of clay minerals having polytypes namely kaolinite, dickite and nacrite and a polymorph called halloysite [1]. It is commonly identified as white and soft clay that exhibits plasticity with the composition of fine-grained plate-like particles. It is formed from the alteration of anhydrous aluminate silicates in feldspar rich rocks like granite through weathering or hydrothermal processes. The microstructure of kaolin comprises grains with a number of different morphologies such as regular and irregular hexagonal platelets, rolled sheets, co-axial sheets, and sometimes tubes [2]. The clay is layered silica mineral, with one tetrahedral sheet linked through oxygen atoms to one octahedral sheet of alumina octahedral [3]. Such description implies that kaolin is suitable to be used as a natural pozzolan. Pozzolanic materials, of natural or artificial origin, contain a high percentage of amorphous silica and a high specific surface in order to generate a pozzolanic reaction [4]. This makes the clay capable of rendering the formation of secondary cementation bonds as a result of its high reactivity to calcium hydroxide generated from cement hydration process.

It is generally recognized that kaolin can be used as a natural pozzolan to partially replace cement in civil engineering applications. In building construction, the clay after calcining is known to possess a great pozzolanic activity that can enhance the strength and durability of mortars and concretes as evident in the finding of several studies [5-8]. Also, it was found in several geotechnical laboratory investigations [9-11] that lime can effectively improve the mechanical properties of kaolin when intimately mixed with the saturated clay. Despite such positive development, the use of kaolin as a natural pozzolan for peat stabilization is not completely explored due to the lack of research with reliable results on stabilization of peat. With the wide availability and the great pozzolanic reactivity of kaolin, there is a need for research on novel usage of the clay as partial replacement of cement in stabilized peat for the purpose of deep peat stabilization. Furthermore, the partial replacement of cement with kaolin offers an environmental advantage of reducing the use of cement in the stabilized soil. Cement 
production is highly energy-intensive process involving significant environmental damage with respect to carbon dioxide $\left(\mathrm{CO}_{2}\right)$ production and raw material acquisition [12]. In manufacturing processes, cement industry requires the consumption of large amount of energy which also implies important greenhouse gas emissions [13]. Thus, partial replacement of cement with kaolin in the stabilized soil can reduce energy consumption of cement production and slow down global warming due to release of $\mathrm{CO}_{2}$ from cement production to the atmosphere.

In the field of foundation engineering, kaolin can be used as a pozzolanic additive to partially replace cement in stabilized peat columns. The stabilized peat columns offer economical solutions as deep foundations to support highway embankments constructed on deep peat ground. Deep mixing is a generic term for a large number of methods in which binding agents, often lime or/and cement, are mechanically mixed with the soil [14-16]. Larsson et al. [17] reported that deep mixing is a universally accepted ground improvement technique for the purpose of improving the permeability, strength and deformation properties of mainly soft soils. In spite the establishment of the method for soil stabilization, the type of cementing materials and the homogeneity in mixing remain two crucial factors in deciding the success of deep peat stabilization. In this aspect, the choice and dosage of materials that can be effectively used to stabilize the soil for highway construction must be addressed.

The present study aims to evaluate the effect of kaolin on the strength and permeability of stabilized peat in laboratory. Kaolin is preferred over metakaolin as a pozzolanic material to stabilize the peat despite the fact that metakaolin generates a better pozzolanic effect than kaolin. This is because production of metakaolin is rather energy consuming as it requires substantial heat in its process of calcination. Metakaolin is produced by heating kaolin at a high temperature ranging from 700 to $850 \_C$ [18]. To achieve the aim of the study, a laboratory based experimental program was developed to investigate the engineering properties of both untreated and stabilized peats. The engineering properties of both soils were characterized in term of unconfined compressive strength and coefficient of permeability.

Materials and technique of characterization

Peat investigated in the study was sampled from Sri Nadi village in the area of Klang of the state of Selangor in Malaysia. Initial investigation on the soil was done through visual observation and tests on basic properties of the soil. Through visual observation on the soil from six excavated trial pits, the average ground water level 
was found to be $0.3 \mathrm{~m}$ from the ground surface. The soil was found to be dark brown in color and spongy in nature. The depth of the peat ranged from 1 to $3 \mathrm{~m}$, with the soil underlain by slightly organic grayish clay. Upon squeezing and extruding the peat between fingers, about one-third of the peat escaped between the fingers. The peat residue was very pasty, but showed the plant structure more distinctly than before squeezing. Such descriptions indicate that the peat can be categorized as a moderately highly decomposed peat with a very indistinct plant structure. Based on the fact, the soil can be classified as $\mathrm{H}_{6}$ according to von Post scale of humification. Table 1 summarizes the basic properties of the peat. It can be observed that the soil is characterized by high moisture content, high initial void ratio and low specific gravity. A low pH value of 3.51 implies that the soil is highly acidic. A linear shrinkage of $34 \%$ indicates the soil has low volume stability. High fiber and organic contents of 90 and $96 \%$ respectively, affirm that the soil can be classified as highly organic fibrous peat. From an engineering point of view, the stronger the fibers and the greater their number, the more reinforced is the peat [19].

To enhance hydration reactivity, hydration kinetics for the calcium silicate and calcium aluminate phases in Portland cements can be modified using a variety of additives [20]. Portland composite cement, calcium chloride, kaolin and silica sand were selected as the materials for the peat stabilization. The Portland composite cement is special cement formulated with addition of $2 \%$ superplasticizer per unit weight of cement to stabilize highly organic soil such as peat. The type of superplasticizer added to the cement is polycarboxylate. Addition of the superplasticizer helped to disperse the cement in the soil during hydration process, thus reducing the soil porosity and permeability. Four percent calcium chloride by weight of the cement was added to the Portland composite cement to function as a cement accelerator. Alkaline salt such as calcium chloride may act as cement accelerator because it increases the heat evolution during the early hydration [21-24]. Basically, calcium chloride was utilized to speed up the hydration reaction of the stabilized soil. An acceleration of the hydration of calcium silicate phases can also be achieved using admixtures with very small particle sizes such as clay minerals [25]. Hence, refined kaolin of Grade KM 90 supplied by Kaolin (Malaysia) Holdings was used as a natural pozzolan for the soil stabilization. The refined kaolin has a $\mathrm{pH}$ ranging from 3.5 to 6.0 , and $85 \%$ to $91 \%$ particles with diameters less than $2 \mathrm{~lm}$.

If dense specimen is to be produced, it is important that the soil used is well graded [26]. Densification of stabilized peat can be achieved with an inclusion of a suitable dosage of well graded silica sand. Well grading of silica sand is necessary considering the fact that void spaces within the stabilized soil is reduced to a minimum when it is well packed with coarse grained sand having the interstices in between filled with fine grained sand. To ensure well grading of the sand, the sand composition was formulated in such a way that out of the $100 \%$ composition of the sand dosage, $6.8 \%, 13.2 \%, 10 \%, 25 \%, 30 \%$ and $15 \%$ sand should retain at $1.18 \mathrm{~mm}, 600,425,300,150$ and $75 \mathrm{~lm}$ sieve sizes, respectively.

Table 2 shows the chemical compositions of the materials, by percentage weight, of the stabilized peat from X-ray Fluorescence (XRF) tests. The XRF equipment cannot be used to characterize the elemental composition of calcium chloride due to the high affinity of the salt for atmospheric moisture. The concentration of $7.300 \% \mathrm{CO}_{2}$ compound in Portland composite cement proves the existence of a small quantity of superplasticizer in the cement to enhance its workability and dispersibility. For kaolin, the sum of such elements as silica $\left(\mathrm{SiO}_{2}\right)$, alumina $\left(\mathrm{Al}_{2} \mathrm{O}_{3}\right)$ and ferric oxide ( $\mathrm{Fe}_{2} \mathrm{O}_{3}$ ) is $96.643 \%$ of the total chemical composition. Billong et al. [27] have clarified that such an amount of elemental content is acceptable because it is greater than $70 \%$ as recommended by ASTM C 618 standard for this type of pozzolan. A chemical composition of $88.840 \% \mathrm{SiO}_{2}$ affirms that quartz is the major constituent of the silica sand. With less that $5 \% \mathrm{SiO}_{2}$ and $\mathrm{Al}_{2} \mathrm{O}_{3}$, it can be identified that the air dried peat has a very low amount of clay minerals. 
Full text available at :

http://ac.els-cdn.com/S0950061812009014/1-s2.0-S0950061812009014-main.pdf? tid=fdf3e73c-66e4-11e3ba6f-00000aacb362\&acdnat $=1387262125$ 3a115a59c40ddbe6ec1ed58b9f0ae871

http://www.sciencedirect.com/science/article/pii/S0950061812009014 